\title{
Can We Predict Delivery Prior to Date of a Planned Elective Caesarean Section?
}

\author{
Schulze $\mathbf{B}^{1}$, Mahomed $\mathrm{K}^{2^{*}}$, and Beckmann $\mathbf{M}^{3}$ \\ ${ }^{1}$ Dr. Brittany Schulze, O\&G Registrar, Ipswich Hospital, Ipswich, QLD 4305 \\ ${ }^{2}$ Assoc. Prof. Kassam Mahomed, Senior Staff Specialist, Department of Obstetrics \& Gynaecology, Ipswich Hospital and University of \\ Queensland, Ipswich, QLD 4305
}

${ }^{3}$ Dr. Michael Beckmann, Director Mothers, Babies and Women's Health Services, Mater Health Services, South Brisbane, QLD 4001

Received: September 09, 2017; Accepted: September 17, 2017; Published: October 13, 2017

*Corresponding author: Assoc. Prof. Kassam Mahomed, Senior Staff Specialist, Department of Obstetrics \& Gynaecology, Ipswich Hospital and University of Queensland, Chelmsford Avenue, Ipswich, QLD 4305;E-mail: Kassam.Mahomed@health.qld.gov.au

\section{Abstract}

Objective: To document frequency and identify risk factors associated with early delivery in women who require caesarean section prior to their planned elective caesarean section date. Additionally, we compared the maternal and neonatal outcomes for those women booked for an elective caesarean section who did and who did not require delivery prior to their booked elective caesarean section (BECS) date.
\end{abstract}

Methods: This was a case controlled study over three years at an outer metropolitan hospital, analysing all low risk women who were booked for an elective caesarean section. Medical records, only of women with a first trimester scan to confirm gestational age, were reviewed. Predefined demographic, maternal and neonatal outcomes were entered into an excel spread sheet for analysis.

Results: Out of a total of 677 women, 76 (11.2\%) booked for an elective caesarean section required delivery prior to their BECS date. Women with previous preterm delivery (prior to 259 days' gestation (K37)) and a current non-cephalic presentation were at higher risk of requiring earlier delivery. Maternal and neonatal outcomes in the two groups are presented.

Conclusions: Women with a current non-cephalic presentation and prior pre-term delivery before 37 weeks' gestation have a higher likelihood of requiring earlier delivery. A prospective study is required to see if an earlier timed c-section could potentially improve maternal and neonatal outcomes as well as optimising limited resources in a peripheral centre.

Keywords: Caesarean Section; Elective delivery; Obstetrics; Labour; Risk Factors; Resource allocation

\section{Background}

More than one in three pregnant women in Australia will give birth by caesarean section (CS) , and more commonly as an elective/planned CS rather than by emergency CS. The most common indication for CS remains a repeat CS [1].

Most clinical practice guidelines recommend undertaking elective CS for uncomplicated pregnancies at or after 39 weeks' gestation to minimise the risk of neonatal respiratory morbidity [2]. This would mean that some women (approximately 10\%) will go into spontaneous labour before BECS date resulting in an intra-partum emergency caesarean section [3-5].

Retrospective cohort studies have shown that after-hours births, especially overnight and on weekends, are associated with poorer neonatal and maternal outcomes, such as low APGAR scores and intrapartum/early neonatal death6. Apart from the impact on staffing and difficulty in accessing theatres, studies have also shown that having an emergency CS in labour, compared with an elective CS, is associated with higher maternal complications, particularly those related to anaesthesia and perioperative bleeding [7-10].

It is difficult to predict which women will need to birth prior to their BECS date. Although there are identifiable risk factors for preterm birth, such as BMI $>35$, advanced maternal age and previous preterm births, there is little data that might assist clinicians when planning the CS date $[11,12]$. Some women, especially those who live further away from the hospital, may want to know their chance of going into labour before their BECS date. Availability of such information may allow clinicians to optimise decision making regarding the CS date. This would not only potentially reduce maternal/neonatal risks associated with emergency CS, but also minimise the effect on staffing and resource allocation associated with emergency, especially afterhours, CS.

The aim of the study was to document the rate of earlier birth than the BECS date in a low-risk population of women booked for an elective CS, report the maternal and neonatal outcomes for those who did and did not need to be birthed prior to their BECS date, and attempt to identify any predictive factors associated with requirement for earlier delivery.

\section{Materials and Methods}

This was a retrospective case controlled study using routinely collected data, of all women with a singleton pregnancy, booked 
for elective CS at 39 weeks' gestation, who delivered on or after 259 days' gestation (37 weeks) between January 1, 2011 and December 31, 2014 at Ipswich Hospital, Ipswich, Queensland. Cases being delivery before elective date and controls being delivery on elective date. Only women with certain gestational age, based on a first trimester dating scan with a crown rump length $\geq 10 \mathrm{~mm}$, were included in the cohort. All charts were reviewed by the principal author.

Medical and obstetric co-morbidities were reported. Medical issues analysed included pre-existing and gestational diabetes mellitus, hypertension, epilepsy, thyroid conditions and other systemic conditions. Obstetric complications analysed included diabetes in pregnancy, hypertensive disorders and fetal growth restriction. Maternal outcomes analysed included post-partum haemorrhage $(>1000 \mathrm{ml})$, blood transfusion, maternal pyrexia, visceral injury (bowel/bladder/other organ damage), wound infection, spinal headache or return to theatre. Neonatal outcomes analysed included birth weight, gender, Apgar scores at 1 and 5 minutes, need for resuscitation, admission to specialcare nursery ( $\mathrm{SCN}$ ) and length of stay. As this was an exploratory study, power calculations were not performed and a three-year period was chosen for convenience.

Data was entered into an excel spread sheet. Data analysis was undertaken using status version 10.1 (statacorp, College Station, TX, USA). Categorical data were compared using chisquare and Fisher's exact test, and continuous data compared using the Student's t-test if normally distributed or the MannWhitney U test if not normally distributed. Regression models were employed to identify characteristics associated with an increased risk of birthing before the BECS date. In the multivariable analyses, a backwards elimination approach was used to progressively remove the least significant terms until all terms remaining were statistically significant $(\mathrm{P}<0.05$, twosided). Crude and adjusted relative risks (RR) were estimated using log-binomial regression to determine which factors were independently associated with delivery prior to BECS date. The final model for analysis included BMI, ethnicity (Caucasian/ Asian), smoking status, non-cephalic presentation, previous caesarean sections ( 1 previous $/ \geq 2$ previous), any medical illness, diabetes in pregnancy and previous delivery $\leq 37$ weeks' gestation.

Ethics approval was sought from the Health Research Ethics Committee (HREC), who deemed the study to have met the requirements for low/negligible risk research (Reference Number: HREC/12/QWMS/49).

\section{Results}

\section{Incidence and Predictive Factors}

A total of 11,369 women gave birth at Ipswich Hospital over the study period, 1583 of whom were booked for an elective CS. After exclusions, 677 women were identified as the study population. Seventy-six women $(11.2 \%)$ had their CS prior to their BECS date.

(Table 1) shows that the baseline characteristics of both groups were similar with respect to age, ethnicity, relationship status, parity $\geq 3$ and previous caesarean sections $\geq 2$. Women who required earlier CS had a lower mean BMI (27.1 vs 28.7; $\mathrm{p}=0.03$ ), and were more likely to have previously delivered at less than 39 weeks' gestation $(49.3 \%$ vs $26.8 \%$; $p<0.01)$ or less than 37 weeks gestation $(15.5 \%$ vs $6.7 \%$; $p=0.01)$, compared to women who birthed on their BECS date.

Table 1: Demographic and clinical baseline characteristics

\begin{tabular}{|c|c|c|c|}
\hline Characteristic & Delivery Prior to BECS N=76, N (\%) & Elective Caesarean $\mathrm{N}=601, \mathrm{~N}(\%)$ & P Value \\
\hline Mean age (SD) & $29.0(5.5)$ & $29.3(5.2)$ & \multirow{3}{*}{0.35} \\
\hline$\leq 18$ years & $3(2.8)$ & $3(0.5)$ & \\
\hline$\geq 35$ years & $17(15.7)$ & $101(16.8)$ & \\
\hline BMI (Mean) & $27.1(7.5)$ & $28.7(7.2)$ & \multirow{4}{*}{0.03} \\
\hline $18-29 \mathrm{~kg} / \mathrm{m} 2$ & $73(67.6)$ & $367(61.1)$ & \\
\hline $30-39 \mathrm{~kg} / \mathrm{m} 2$ & $23(21.3)$ & $183(30.4)$ & \\
\hline$\geq 40 \mathrm{~kg} / \mathrm{m} 2$ & $9(9.3)$ & $56(9.3)$ & \\
\hline Caucasian & $58(76.3)$ & $495(82.8)$ & 0.17 \\
\hline Married/De facto & $66(86.8)$ & $513(85.8)$ & 0.8 \\
\hline $\mathrm{EDPS}^{1} \geq 13$ & $6(8.1)$ & $33(5.6)$ & 0.38 \\
\hline Any medical illness ${ }^{2}$ & $14(18.4)$ & $149(24.8)$ & 0.22 \\
\hline Obstetric complications & $23(30.3)$ & $156(26.0)$ & 0.42 \\
\hline Diabetes in pregnancy ${ }^{3}$ & $11(14.5)$ & $57(9.5)$ & 0.17 \\
\hline
\end{tabular}




\begin{tabular}{|c|c|c|c|}
\hline Hypertensive disorders $^{4}$ & $5(6.6)$ & $49(8.1)$ & 0.39 \\
\hline Nulliparous & $5(6.6)$ & $60(10.0)$ & 0.34 \\
\hline Parity $\geq 3$ & $16(21.1)$ & $126(21.0)$ & 0.99 \\
\hline Number of previous caesarean $\geq 2$ & $25(34.7)$ & $206(34.3)$ & 0.72 \\
\hline Previous birth <273 days & $35(49.3)$ & $160(26.8)$ & $<0.01$ \\
\hline Previous birth <259 days & $11(15.5)$ & $36(6.7)$ & 0.01 \\
\hline $\begin{array}{c}\text { Cephalic presentation (current } \\
\text { pregnancy) }\end{array}$ & $60(78.9)$ & $524(87.3)$ & 0.05 \\
\hline $\begin{array}{c}\text { Breech presentation (current } \\
\text { pregnancy) }\end{array}$ & $16(21.1)$ & $69(11.5)$ & 0.01 \\
\hline
\end{tabular}

${ }^{1}$ Edinburgh Postnatal Depression Scale

${ }^{2}$ Any medical illness, defined as significant illness requiring medication, including: CNS abnormalities, cardiovascular disease, diabetes, epilepsy, herpes, psychiatric, renal disease, respiratory disease, substance abuse, thyroid disease and hematological disease.

${ }^{3}$ Diabetes in pregnancy included: gestational diabetes (diet or medication required) or pre-existing diabetes (Type 1 or Type 2).

${ }^{4}$ Hypertensive disorders, including: gestational hypertension, pre-eclampsia/HELLP syndrome or essential hypertension.

Following multivariate analysis, both a non-cephalic presentation in current pregnancy (aor $=2.46(95 \%$ CI $1.20-5.07)$; $\mathrm{p}=0.01)$ and a previous delivery less than 37 weeks' gestation (aor $=2.40(95 \% \mathrm{CI}=1.13-5.10) ; \mathrm{p}=0.02)$, were associated with increased odds of delivery prior to BECS (Table 2).

Table 2: Factors associated with delivery prior to BECS: multivariate logistic regression

\begin{tabular}{|c|c|c|c|}
\hline Factor & $\begin{array}{c}\text { Adjusted Odds } \\
\text { Ratio }\end{array}$ & $95 \% \mathrm{CI}$ & $P$ Value \\
\hline BMI & 0.97 & $0.93-1.01$ & 0.09 \\
\hline \multicolumn{4}{|c|}{ Ethnicity } \\
\hline Caucasian & 1.79 & $0.65-4.93$ & 0.26 \\
\hline Asian & 1.47 & $0.73-2.98$ & 0.28 \\
\hline Smoking & 0.86 & $0.46-1.61$ & 0.64 \\
\hline $\begin{array}{l}\text { Non-cephalic } \\
\text { presentation }\end{array}$ & 2.46 & $1.20-5.07$ & 0.01 \\
\hline \multicolumn{4}{|c|}{ Previous caesarean } \\
\hline one previous & 0.77 & $0.36-2.44$ & 0.51 \\
\hline two or more previous & 0.81 & $0.36-1.82$ & 0.07 \\
\hline Any medical illness ${ }^{1}$ & 0.93 & $0.49-1.78$ & 0.83 \\
\hline Diabetes in pregnancy ${ }^{2}$ & 1.41 & $0.63-3.14$ & 0.4 \\
\hline $\begin{array}{c}\text { Previous delivery } \leq 37 \\
\text { weeks gestation }\end{array}$ & 2.4 & $1.13-5.10$ & 0.02 \\
\hline
\end{tabular}

${ }^{1}$ Any medical illness, defined as significant illness requiring medication, including: CNS abnormalities, cardiovascular disease, diabetes, epilepsy, herpes, psychiatric, renal disease, respiratory disease, substance abuse, thyroid disease and haematological disease.

${ }^{2}$ Diabetes in pregnancy, including: gestational diabetes (diet/medication required) or pre-existing diabetes (Type 1 or Type 2).

\section{Maternal and Neonatal Outcomes}

There were no statistical differences found in regards to maternal outcomes between the group who delivered prior to or on their BECS date with respect to visceral injury at CS, blood loss $(>1000 \mathrm{ml})$, blood transfusion, spinal headache, return to theatre, admission to ICU, prolonged hospital admission ( $>72$ hours), maternal wound infection or maternal morbidity (Table 3).

Table 3: Maternal outcomes

\begin{tabular}{|c|c|c|c|}
\hline Outcome & $\begin{array}{c}\text { Delivery Prior } \\
\text { to BECS N=76, } \\
\mathbf{N ( \% )}\end{array}$ & $\begin{array}{c}\text { Elective } \\
\text { Caesarean } \\
\text { N=601, } \\
\text { N(\%) }\end{array}$ & P Value \\
\hline Visceral injury at CS & $1(1.3 \%)$ & $16(2.7 \%)$ & 0.41 \\
\hline Blood loss $>1000 \mathrm{~mL}$ & $4(5.3 \%)$ & $23(3.8 \%)$ & 0.55 \\
\hline Maternal wound infection ${ }^{1}$ & $0(0 \%)$ & $2(0.3 \%)$ & 0.79 \\
\hline Blood transfusion & $3(3.9 \%)$ & $5(0.8 \%)$ & 0.05 \\
\hline Spinal headache & $1(1.3 \%)$ & $12(2.0 \%)$ & 0.56 \\
\hline Unplanned return to theatre & $1(1.3 \%)$ & $5(0.8 \%)$ & 0.51 \\
\hline Maternal morbidity & $7(9.2 \%)$ & $46(7.7 \%)$ & 0.38 \\
\hline ICU admission & $0(0 \%)$ & $1(0.2 \%)$ & 0.89 \\
\hline Hospital admission $>72$ hours & $28(36.8 \%)$ & $91(15.1 \%)$ & 0.99 \\
\hline
\end{tabular}

${ }^{1}$ Maternal wound infection determined by pyrexia, wound erythematic, wound discharge or requirement for antibiotics.

${ }^{2}$ Maternal morbidity included post-partum haemorrhage, blood transfusion, and maternal pyrexia or wound infection.

In terms of neonatal outcomes, babies born prior to BECS date were lighter (3273g versus 3523g, $\mathrm{p}<0.001$ ), were more likely to require antibiotic administration $(6.6 \%$ vs $2.0 \% \mathrm{p}=0.03)$, to be suspected of sepsis $(5.3 \%$ vs $1.2 \%, p=0.03)$ and have longer stay in SCN (3.7 vs 0.28 days, $\mathrm{p}<0.001$ ) (Table 4). 
Table 4: Neonatal outcomes (limited by those $>259$ days)

\begin{tabular}{|c|c|c|c|}
\hline Outcome & Delivery Prior to BECS N=76, N (\%) & Elective Caesarean $\mathrm{N}=601, \mathrm{~N}(\%)$ & $P$ value \\
\hline Birth weight $(g)^{1}$ & $3273(549)$ & $3523(508)$ & $<0.01$ \\
\hline APGAR $<7$ at 5 minutes & $0(0)$ & $1(0.2)$ & 0.72 \\
\hline Resuscitation $^{2}$ & $19(25.0)$ & $105(17.5)$ & 0.11 \\
\hline Admission to SCN & $4(5.3)$ & $55(9.2)$ & 0.26 \\
\hline Duration in SCN (mean days) & 3.7 & 0.28 & $<0.01$ \\
\hline Sepsis-suspected & $4(5.3)$ & $7(1.2)$ & 0.03 \\
\hline Sepsis-proven & $1(1.3)$ & $0(0)$ & 0.11 \\
\hline Antibiotic administration & $5(6.6)$ & $12(2.0)$ & 0.03 \\
\hline Hypoglycaemia & $1(1.3)$ & $8(1.3)$ & 0.73 \\
\hline Phototherapy & $1(1.3)$ & $4(0.7)$ & 0.45 \\
\hline Seizures & $0(0)$ & $0(0)$ & 0.99 \\
\hline Short-term respiratory morbidity ${ }^{3}$ & $10(13.2)$ & $45(7.5)$ & 0.09 \\
\hline \multicolumn{4}{|l|}{ Mean (SD). } \\
\hline \multicolumn{4}{|c|}{ Resuscitation including suction and stimulation, facial oxygen, bag and mask, ventilation and intubation or PEEP. } \\
\hline \multicolumn{4}{|c|}{$\begin{array}{l}\text { Short term respiratory morbidity included: respiratory distress syndrome, transient tachypnoea of newborn, admission to special care nursery }>4 \\
\text { hours and/or APGARs } \leq 7 \text { at } 5 \text { minutes of life. }\end{array}$} \\
\hline
\end{tabular}

\section{Discussion}

As demonstrated in other studies, we observed that approximately 1 in 10 otherwise low-risk women will labour prior to their BECS date. Where there is a current non-cephalic presentation and/or a previous preterm birth ( $<259$ days), the likelihood of a woman requiring delivery prior to BECS date appears to be greater [3].

There is surprisingly little literature on the risk factors for birth prior to BECS date. Our observation of an association between non-cephalic presentation and delivery prior to BECS has not been reported previously. The association with a previous preterm birth (prior to 259 days/37+0 weeks), has however been reported by others. In a recent systematic review, Roberts et al reported that women pregnant with a singleton pregnancy following a previous preterm singleton birth had an absolute recurrence risk of $20 \%$ (95\% CI 19.9-20.6) [10]. Others have also noted an association between delivery prior to BECS and ethnicity (specifically Asian), smoking and having had two or more previous CS, although we were not able to confirm their findings Many clinical practice guidelines recommend elective CS after 39 weeks in low-risk women to reduce the risk of neonatal respiratory morbidity. However, knowing the likelihood of spontaneous labour prior to BECS date can be useful in planning the place and time of birth, especially for women who live remotely [3-5,13]. Although we did not show any difference in maternal morbidity (possibly due to our small sample size), delivery prior to BECS performed as an emergency case may be associated with increased maternal and neonatal morbidity [14]. Particularly after-hours emergency cases, which may be associated with increased risks [6]. Perhaps counselling and advice for some women (eg. Non-cephalic presentation and/ or prior preterm birth) should include a discussion of planned delivery prior to the recommended 39 weeks' gestation. There is certainly a need to discuss options of timing their caesarean section in order to optimise maternal and neonatal outcomes. Whilst the gestation at birth will be a factor contributing to the additional maternal and perinatal morbidity observed when delivery occurs prior to BECS, some of this additional morbidity will also reflect the more emergent nature of the delivery, and the clinical reason that gave rise to the need for earlier delivery. Regardless, there is a clear impact upon the healthcare system (particularly in smaller maternity services) when scheduled work becomes unscheduled work. Future researchers should consider the clinical, experiential, and cost implications of scheduling selected women for an earlier elective CS.

We acknowledge several limitations in this study. This analysis was based on retrospective manual chart review, of a relatively small number of cases, and undertaken at a single centre. Missing data is acknowledged, especially gestational age of previous births $(\mathrm{n}=70)$ and presentation $(\mathrm{n}=1)$. Although the data was extracted by a single investigator (BS), most information was inferred from free-text entries and therefore there is the potential for entry-error and/or misclassification of clinical information. Additionally, women with severe medical and obstetric co-morbidities were excluded from the analysis, limiting the generalisability of the results. Furthermore, the analyses controlled only for certain confounders and hence different statistical models using different data may have reached different conclusions. 


\section{Conclusion}

Women with a current non-cephalic presentation and a previous pre-term delivery before 37 weeks' gestation have a higher likelihood of requiring earlier delivery and it may be beneficial to discuss options of timing their caesarean section in order to optimise not only maternal and neonatal outcomes, but also staffing and other resource implications.

\section{Acknowledgements}

\section{Author Contributions:}

BS correlated methods, data and formulated research review and results. KM assisted in planning the study, data analysis, drafting the paper. MB assisted with data analysis and drafting the paper. All members have reviewed final article prior to submission.

\section{References}

1. Australia's Mothers and Babies In Brief. Australian Institute of Health \& Wellbeing (AIWH). 2013.

2. Morrison J, Rennice J and Milton P. Neonatal respiratory morbidity and mode of delivery at term: influence of timing of elective CS. Br J Obstet Gynaecol. 1995;102(2):101-106.

3. Roberts CL, Nicholl MC, Algert CS, Ford JB, Morris JM and Chen JS Rate of spontaneous onset of labour before planned repeat CS at term. BMC Pregnancy and Childbirth. 2014;14:125-129.

4. RANZCOG. Timing of elective caesarean section at term. November 2006.

5. NICE. Caesarean Section: Clinical guidelines (CG132). November 2011.

6. Gijsen R, Hukkelhoven CW, Schipper CM, Ogbu UC, de BruinKooistra M, Westert GP. Effects of hospital delivery during off-hours on perinatal outcome in several subgroups: a retrospective cohort study. BMC Pregnancy and Childbirth. September 2012;12:92. Doi: 10.1186/1471-2393-12-92
7. Hassan S, Tariq S, Javaid MK. Emergency CS: Comparative analysis of problems encountered between patients of elective CS and patient for whom elective CS was planned but ended up in emergency. Professional Med J. 2008; 15(2): 211-215.

8. Ghazi A, Karim F, Hussain AM, Ali T, Jabbar S. Maternal morbidity in emergency versus elective CS at a tertiary care hospital. J Ayub Med Coll Abbottabad. 2012;24(1):10-13.

9. Hannah, ME. Planned elective CS: A reasonable choice for some women? CMAJ. 2004;170(5):813-814.

10. Roberts CL, Ford JB, Algert CS, Bell JC, Simpson JM, Morris JM. Trends in adverse maternal outcomes during childbirth: a population-based study of severe maternal morbidity. BMC Pregnancy Childbirth. 2009,9:7. Doi: 10.1186/1471-2393-9-7

11. Torloni MR, Betrán AP, Daher S, Widmer M, Dolan SM, Menon R, Bergel E, Allen T, Merialdi M. Maternal BMI and preterm birth: A systematic review of the literature with meta-analysis. Journal of Maternal-Fetal \& Neonatal Medicine. 2009; 22(11): 957-970. Doi: $10.3109 / 14767050903042561$

12. Kazemier BM, Buijs PE, Mignini L, Limpens J, de Groot CJ, Mol B. Impact of obstetric history on the risk of spontaneous preterm birth in singleton and multiple pregnancies: a systematic review. BJOG. 2014; 121(10):1197-1208. Doi: 10.1111/1471-0528.12896

13. ACOG. Caesarean delivery on maternal request. Committee Opinion No. 559. Obstet Gynecol 2013;121(4):904-907.

14. Ganchimeg T, Nagata C, Vogel JP, Morisaki N, Pileggi-Castro C, OrtizPanozo E, Jayaratne K, Mittal S, Ota E, Souza JP, Mori R. Optimal Timing of Delivery among Low-Risk Women with Prior Caesarean Section: A Secondary Analysis of the WHO Multi country Survey on Maternal and Newborn Health. PLoS ONE. 2016;11(2):e0149091. 